\title{
Communication Strategies for Family Physicians Practicing Throughout Emerging Public Health Crises
}

Christy J.W. Ledford, PhD; LaKesha N. Anderson, PhD

(Fam Med. 2020;52(5):320-3.)

doi: 10.22454/FamMed.2020.960734

I n times of public health crisis such as pandemic illness, family physicians must be effective risk communicators. A lack of information or misunderstanding can lead to unproductive panic about a public health threat or an underestimation of the threat, which can thwart efforts to limit contagion. In these crisis situations, people are easily confused about the nature of pandemic illness and what steps to take to avoid it. People seek credible public health officials or other trusted health care professionals, like physicians, to provide information. ${ }^{1}$ Risk communication theory and evidence provides a framework for physicians to consider during such times.

Risk communication serves two primary functions: to alert people and to reassure them. ${ }^{2}$ The challenging task of simultaneously alerting and reassuring people is familiar to family physicians, who are daily charged with providing preventive care advice to their patients. Just as family physicians alert and reassure expectant parents about childbirth decisions, new parents about childhood vaccines, and adults about cancer screening choices, family physicians play a key role in alerting and reassuring patients in times of pandemic illness.

Risk communication sits at the intersection of hazard and outrage.
Hazard is the physical risk as understood by scientists and experts; outrage is the public's perception of that risk. ${ }^{2}$ In risk communication, it is critical to manage the hazard and address the outrage. People often overestimate risk while ignoring the physical hazard. In the context of a viral pandemic, public outrage will be greater when the illness is unfamiliar, when there is some memorability of past pandemic illnesses, when there is substantial dread associated with the illness, when illness spreads quickly or deaths occur frequently, and when uncertainty surrounds the illness. As the medical community serves our patients through the outbreak of novel coronavirus disease 2019 (SARS-CoV-2, also known as COVID-19), these outrage factors are particularly poignant.

Outrage can impede the public from hearing risk messages clearly. High outrage reduces objectivity and motivates action. ${ }^{2}$ The internet and social media as a dissemination tool for news enables the public to hear about physical hazards more quickly than ever, even before scientists fully understand the transmission or impact of disease. ${ }^{3}$ The World Health Organization and Centers for Disease Control and Prevention constantly update the public on the facts and figures of the disease, which quantifies the spread and marks milestones such as surpassing 100,000 cases. ${ }^{4}$ News and social organizations then contextualize those figures with comparisons to past viral outbreaks, ${ }^{5}$ such as SARS or H1N1, providing visual reminders of masks on subways and cancelled airline travel.

Although this information is intended to be helpful, when people are outraged, they are less likely to listen to hazard data or read charts. Instead, they are more likely to respond emotionally, motivated by feelings of panic and dread. An outraged public can, however, be beneficial. High levels of outrage highlight serious risks. The role of the risk communicator is to match the level of outrage to the seriousness of the hazard. Risk scientist Peter Sandman, $\mathrm{PhD}$ suggests several ways to achieve this: making the risk seem more familiar, legitimating dread, increasing knowability, taking catastrophe seriously, building trust, and responding to the public's concerns and questions. ${ }^{2}$

Dr Katherine Rowan's CAUSE model provides a framework for talking to patients about what actions

From the Uniformed Services University of the Health Sciences, Bethesda, MD (Dr Ledford); and the National Communication Association, Washington, DC (Dr Anderson). 
can mitigate a risk. ${ }^{6}$ The primary messages in pandemics involve communication that is intended to alter behavior such as handwashing and social distancing. ${ }^{7} \mathrm{Her}$ framework establishes five communicative goals: create confidence, generate awareness, enhance understanding, gain satisfaction, and motivate action, or enactment. Previous research has applied this model to physician discussion of cancer risk, ${ }^{6}$ training for emergency managers in crisis response, ${ }^{8}$ and pharmaceutical communication in a medical recall. ${ }^{9}$ Table 1 presents theory-informed strategies for family physicians to communicate about risk throughout a viral outbreak.

Within the CAUSE framework, the family physician is well positioned to be a source of risk information because family physicians have established relationships within the community, relationships through which they have already earned the confidence of patients. Confidence is a function of source credibility, and refers to the judgments listeners make about the expertise and trustworthiness of the information source. ${ }^{10}$ Family physicians are demonstrated experts in personal health and are trusted by their patients.
Ideally, patients have established relationships with them. This affords a major advantage compared to unknown expert sources of information in the media. As credible health information sources, family physicians can deliver more receptive messages ${ }^{11,12}$ including increasing patients' perception of a health threat, as well as improving their efficacy. ${ }^{13}$

Family physicians can boost the trust dimension of credibility by using alternative, but still synchronous forms of communication. ${ }^{14}$ In response to COVID-19 precautions, many physicians have closed their offices to face-to-face visits. As a

Table 1: Theory-Informed Strategies for Family Physicians to Communicate About Risk Throughout a Viral Outbreak

\begin{tabular}{|c|c|c|}
\hline Stage in CAUSE Model & Strategy & Proposed Actions \\
\hline \multirow[t]{4}{*}{ Create confidence } & Build trust & $\begin{array}{l}\text { - Continue current practices of relationship building with } \\
\text { patients. } \\
\text { - Provide electronic visits and virtual check-ins. } \\
\text { - Tell the truth about risk. } \\
\text { - Engage in active listening. } \\
\text { - Encourage patients to do additional research or seek second } \\
\text { opinions. }\end{array}$ \\
\hline & Establish expertise & - Explain how clinical judgments are made. \\
\hline & \multirow[b]{2}{*}{ Legitimate dread } & - Expect patient responses like fear and anger. \\
\hline & & $\begin{array}{l}\text { - Use empathic statements to legitimate patient feelings about } \\
\text { the risk. }\end{array}$ \\
\hline Generate awareness & & $\begin{array}{l}\text { - Post visible, simple information in the clinic. } \\
\text { - Use simple language during appointments. }\end{array}$ \\
\hline \multirow{3}{*}{ Enhance understanding } & Increase knowability & $\begin{array}{l}\text { - Provide "information prescriptions." } \\
\text { - Present numerical data visually. } \\
\text { - Explain likelihood of risk. }\end{array}$ \\
\hline & $\begin{array}{l}\text { Make the risk seem more } \\
\text { familiar }\end{array}$ & - Provide examples of what the hazard is (and what it is not). \\
\hline & $\begin{array}{l}\text { Respond to patient } \\
\text { concerns and questions }\end{array}$ & $\begin{array}{l}\text { - Prepare all clinical staff to answer patient questions - this } \\
\text { may be simply knowing who to ask to find answers for the } \\
\text { patients. }\end{array}$ \\
\hline Gain satisfaction & $\begin{array}{l}\text { Outline specific actions to } \\
\text { mitigate the threat }\end{array}$ & $\begin{array}{l}\text { - Tell patients what the specific actions appropriate to their risk } \\
\text { levels are. } \\
\text { - Encourage reconsideration when patient underestimates risk. } \\
\text { - Praise patients heeding medical advice. }\end{array}$ \\
\hline \multirow{5}{*}{$\begin{array}{l}\text { Motivate action } \\
\text { (enactment) }\end{array}$} & \multirow{3}{*}{ Use efficacy messages } & $\begin{array}{l}\text { - Provide clear instruction. } \\
\text { - Make first request easy to complete. } \\
\text { - Praise patient successes. }\end{array}$ \\
\hline & & - Direct patients to how-to videos online. \\
\hline & & $\begin{array}{l}\text { - Provide "practice stations" in the clinic for patients to try a new } \\
\text { behavior and receive feedback about performance. }\end{array}$ \\
\hline & \multirow{2}{*}{ Provide resources if needed } & $\begin{array}{l}\text { - Patients may need prescriptions or directions for how to obtain } \\
\text { specific items. }\end{array}$ \\
\hline & & $\begin{array}{l}\text { - Know what the local rules and expectations for providing } \\
\text { patients documentation for social distancing are. }\end{array}$ \\
\hline
\end{tabular}


result, other channels of communication are being utilized to reach a continually growing patient population. Telemedicine, by both phone and computer, will play a key role in timely, interactive communication and health care delivery while keeping health care workers and patients safe. Ways of enacting telemedicine include using phone calls to reach out to patients before they enter the clinical setting, offering electronic appointments, and providing virtual check-ins where patients can initiate communication with physicians. Additionally, having staff available to help patients navigate these new systems is critical to their successful implementation. Each of these steps communicates caring and serves to maintain trust during a confusing time for many patients.

Family physicians also have a role to play in generating awareness of potential public health risks. Simple, informational messages should be both visible and easily understood and paraphrased for an audience. ${ }^{15}$ Physicians and clinic staff should be prepared to answer questions about signage or patient information handouts, even if only to tell patients where they can find the answers to their questions. Physicians should use simple, jargon-free language to explain health risks to patients during appointments.

It is not enough to make patients aware of an emerging health crisis. Family physicians must also enhance understanding of the health crisis and reasons for health behavior changes, including, in this context, severity of and susceptibility to potential exposure. During an emerging crisis, achieving patient understanding is challenging because of the dynamic nature of information. Family physicians can also give patients an "information prescription," directing them to credible, comprehensive internet resources such as the Centers for Disease Control and Prevention's website or state or county public health department websites. ${ }^{16,17}$ In previous research, physicians who used information prescriptions reported that it promoted patient efficacy by explaining difficult concepts and medications. ${ }^{18}$ In the case of pandemic illness, physicians can also increase understanding by explaining key terms to patients; explaining what a pandemic illness is and is not; giving examples of past pandemics; explaining the risk (death, illness, organ damage, etc) in terms of likelihood; and furnishing numerical data in a visual way. ${ }^{6}$ Family physicians can communicatively inoculate patients against misinformation by pre-emptively highlighting false claims and refuting potential counterarguments..$^{19,20}$

After patients acknowledge and understand the potential risk, physicians should recommend actions to achieve a specific positive outcome to the crisis. Physicians should concentrate on engaging in patient conversations and answering patient questions to avoid confusion about the specified plan of action. Family physicians, particularly within existing relationships, can include "mobilizing information" ${ }^{11}$ that personalizes risk and recommends steps to enact solutions.

The end goal is enactment. Enactment refers to how well message recipients are adhering to the targeted behavior: are patients washing their hands according to instructions or limiting social exposures successfully? If the previous steps in the model (C-A-U-S) were not followed, it will become evident during this step. Fortunately, increased knowledge and understanding coupled with a satisfactory plan can improve patient efficacy. For example, in the case of COVID-19, patients need to recognize why social distancing is recommended. Patients need to understand that social distancing can prevent disease spread, and then patients need to believe that they can individually take the actions required to socially distance themselves. Only then can patients better understand (1) that proposed actions do, in fact, prevent negative outcomes (response efficacy), and (2) that they have the skills to enact those behaviors (selfefficacy).

For family physicians, who are typically well-respected and trusted in their communities, these risk communication frameworks can help improve physician-patient communication about health crises of various types, and especially pandemics, which can generate high public outrage about a little-known risk. During a health crisis, the public wants clear information that they can act on. Messages that improve knowledge and understanding, while also recognizing emotional responses like fear and anger, can help patients work through their outrage and make better decisions regarding their health. Risk communication is not about only persuading an audience to avoid risk or calming an outraged public. Rather, the appropriate response lies at the intersection of both goals. Physicians can use these risk communication theories to increase attention to serious health crises, like pandemics, where action is needed to avoid a hazard. Physicians can also use these strategies to reduce emotional responses often associated with new health threats.

DISCLAIMER: The views expressed within this publication represent those of the authors and do not reflect the official position of the Uniformed Services University of the Health Sciences, or the US Government, or the Department of Defense at large.

ACKNOWLEDGMENTS: The authors thank Dr Kathy Rowan for teaching us the critical role of risk communication in our everyday world.

CORRESPONDING AUTHOR: Address correspondence to Dr Christy Ledford, Uniformed Services University of the Health Sciences, Department of Family Medicine, 4301 Jones Bridge Road, A1040U, Bethesda, MD 20814. 301-295-0703. Fax: 301-295-3100.

\section{References}

1. Hesse BW, Nelson DE, Kreps GL, et al. Trust and sources of health information: the impact of the Internet and its implications for health care providers: findings from the first Health Information National Trends Survey. Arch Intern Med. 2005;165(22):2618-2624.

2. Sandman PM. Responding to community outrage: Strategies for effective risk communication. Fairfax, VA: American Industrial Hygiene Association; 1993. 
3. Lauer SA, Grantz KH, Bi Q, et al. The Incubation Period of Coronavirus Disease 2019 (COVID-19) From Publicly Reported Confirmed Cases: estimation and Application. Ann Intern Med. 2020.

4. WHO Statement on cases of COVID-19 surpassing 100,000 [press release]. Geneva, Switzerland: World Health Organization; March 7, 2020.

5. Baldwin AN. How novel coronavirus compares to SARS, MERS and other recent viral outbreaks: A look at how COVID-19 stacks up against recent viral epidemics. ABC News. https://abcnews.go.com/US/coronaviruscompares-sars-mers-recent-viral-outbreaks/ story?id=69329364. Published March 2, 2020. Accessed March 12, 2020, 2020.

6. Rowan KE, Sparks L, Pecchioni L, Villagran MM. The CAUSE model: a research-supported aid for physicians communicating with patients about cancer risk. Health Commun. 2003;15(2):235-248.

7. Centers for Disease Control and Prevention. Coronavirus disease 2019 (COVID-19): What you should know. CDC. https://www.cdc.gov/ coronavirus/2019-ncov/downloads/2019-ncovfactsheet.pdf. Published March 20, 2020. Accessed April 3, 2020

8. Rowan KE, Botan CH, Kreps GL, Samoilenko S, Farnsworth K. Risk communication education for local emergency managers: using the CAUSE Model for research, education, and outreach. In: Heath RL, O'Hair HD, eds. Handbook of Crisis and Risk Communication. New York: Taylor and Francis; 2009:168-191.
9. Ledford CJ, Anderson LN. Online social networking in discussions of risk: applying the CAUSE model in a content analysis of Facebook. Health Risk Soc. 2013;15(3):251-264.

10. Nan X. Perceived source credibility and advertising persuasiveness: an investigation of moderators and psychological processes. J Curr Issues Res Advert. 2013;34(2):195-211.

11. Freed GL, Clark SJ, Butchart AT, Singer DC, Davis MM. Sources and perceived credibility of vaccine-safety information for parents. Pediatrics. 2011;127(suppl 1):S107-S112.

12. Paulsel ML, McCroskey JC, Richmond VP. Perceptions of health care professionals' credibility as a predictor of patients' satisfaction with their medical care and physician. Commun Res Rep. 2006;23(2):69-76.

13. De Meulenaer S, De Pelsmacker P, Dens N. Power Distance, Uncertainty Avoidance, and the Effects of Source Credibility on Health Risk Message Compliance. Health Commun. 2018;33(3):291-298.

14. Ledford CJW. Changing channels: a theorybased guide to selecting traditional, new, and social media in strategic social marketing. Soc Mar Q. 2012;18(3):175-186.

15. Rowan KE. Goals, obstacles, and strategies in risk communication: A problem-solving approach to improving communication about risks. J Appl Commun Res. 1991;19(4):300-329.

16. Coberly E, Boren SA, Davis JW, et al. Linking clinic patients to internet-based, conditionspecific information prescriptions. J Med Libr Assoc. 2010;98(2):160-164.
17. Burke M, Carey P, Haines L, Lampson AP, Pond F. Implementing the information prescription protocol in a family medicine practice: a case study. J Med Libr Assoc. 2010;98(3):228234

18. Siegel ER, Logan RA, Harnsberger RL, et al. Information Rx: evaluation of a new informatics tool for physicians, patients, and libraries. Inf Serv Use. 2006;26(1):1-10.

19. van der Linden S, Leiserowitz A, Rosenthal $\mathrm{S}$, Maibach E. Inoculating the public against misinformation about climate change. Global Challenges (Hoboken, NJ). 2017;1(2):1600008.

20. Pfau M. Designing messages for behavioral inoculation. In: Maibach E, Parrott RL, eds. Designing Health Messages: Approaches from Communication Theory and Public Health Practice Thousand Oaks. CA: SAGE Publishing; 1995:99-113.

21. Clarke CE. A case of conflicting norms? Mobilizing and accountability information in newspaper coverage of the autism-vaccine controversy. Public Underst Sci. 2011;20(5):609-626. 